\title{
Industry Practices of Digital Twin Technology Application in the Russian Federation
}

\author{
Natalia S. Zinchik \\ Department of Management and Innovation \\ Saint Petersburg State University of Economics \\ Saint Petersburg, Russia \\ zinchik.n@unecon.ru
}

\section{Elena A. Sintsova}

Department of Management and Innovation

Private Educational Institution St. Petersburg University

ofManagement Technologies and Economics

Saint Petersburg, Russia

sintsova_elena@hotmail.com

\author{
Vladlena E. Zarembo \\ Department of Management and Innovation \\ Saint Petersburg State University of Economics \\ Saint Petersburg, Russia \\ dr.zarembo@gmail.com
}

\author{
Victoria A. Bichurina \\ Department of international finance and accounting \\ Private Educational Institution St. Petersburg University of \\ Management Technologies and Economics \\ Saint Petersburg, Russia \\ bva-2017@yandex.ru
}

\begin{abstract}
The introduction of digital technologies at the enterprises of different economy branches contributes to more intensive transition to the Industry 4.0. It is based on automation and digitalization of all the processes occurring within the activity frames of business units. Digital twins of products and production processes become one of the profusely developing solutions. Their application supports increase of enterprises' competiveness, productivity growth, effective project management along the entire life cycle. The research results presented in this article are intended to determination of the digital twins' role in management and control on the entire enterprise and its operation and project activities, to development of recommendations regarding implementation of the digital twin technology in different industries of the Russian economy. The basic research methods were analysis and assessment of effectiveness of the technology implementation. The factors determining interest of enterprises in implementation of digital twins were analyzed. The areas, mostly actual for implementation of this technology, were defined. The obtained economic results of the technology introduction at the enterprises were investigated. The application domains limiting expansion of the digital twin technology were revealed. The legal safety of the digital solutions and technology availability were analyzed. Additionally, the approaches as data synthesis, comparative analysis, graphic data representation, strategic analysis of digital twin technology impact on development of enterprises were applied. The recommendations of industry related implementation of the digital twin technology were complied, the advantages of enterprises at that implementation based on the analysis of the business units' activity were revealed.
\end{abstract}

Keywords: digital technologies, digital twins, enterprise, transformation of industry

\section{INTRODUCTION}

Automation has been one of industrial growth drivers for decades. It has been providing sustainable competitive advantages and enabling to increase product quality and manage costs effectively. The next technological jump in industrial production was process, product and system digitalization.

Digital economy is based on processing big data and intended to transformation of high-tech production complex into digital industry. Digital technologies may support such trends of year 2020 as hyperautomation, autonomous things, transparency and traceability [11], because maximum cost reduction is impossible without digital process transformation.

One of the directions to build digital economy is introduction of digital twins. This technology has been firstly introduced in 2000-s and within two decades it has become available for most of the companies. However, there are discrepancies in translation of terms and definitions, the technology opportunities are underestimated, there are relatively less scientific approaches to its introduction into industry.

Provision of sustainable introduction of the digital twin technology in industry arises a row of both scientific and practical problems, in particular:

- Transitionary terminology in the field of digital twins;

- Not enough open data on experience of the technology introduction both at Russian and foreign enterprises; 
- Insufficient analysis of branch opportunities of the technology development in the middle-term prospect;

- Absence of complex approach to the technology introduction at an enterprise;

- Insufficient elaboration of information safety issues.

We will consider these problems more detailed.

\section{A. Transitionary terminology in the field of digital twins.}

Currently under the term of a digital twin, principally different approaches to digital product generation are understood. Some companies, scientists, developers believe this is a separate technology enabling creation of a virtual product or virtual production [15]. Thereby all the objects of this system shall be mutually integrated and exchange information operatively.

Other companies understand a digital twin as a complex of technologies [9], providing co-use of elements of computer simulation and IoT (Internet of Things). Digital twin assume an entire copy of already existing and acting physical object reflecting all the physical processes being performed in it [3].

The experiences of Russian enterprises show that a digital twin is a $3 \mathrm{D}$ model of an object generated with standard CAD (computer-aided design) programs into which metrical services enter detailed data of a real object for its further structuring or construction. That is a digital twin is often created before the product is created; it controls stages of design, construction and mounting. Such projects are implemented in shipbuilding and engine building.

Thereby there is no unified approach neither to creation of a digital twin, nor to its purpose and functions it has to fulfill.

\section{B. Not enough open data on experience of the technology introduction both at Russian and foreign enterprises.}

In the Russian Federation, building of digital economy is one of the development priorities. Thereby the information availability via internet for citizens, development of digital platforms, assurance of information safety, and preparation of personnel for digital economy are highlighted [16]. The matters of introduction of digital solutions into activities of enterprises are poorly researched; the program of Digital Economy of the Russian Federation has no benchmarks in this direction. Statistic monitoring also gives data on introduction of ERP (Enterprise Resource Planning), SRM (Supplier relationship management) systems, electronic document flow only, without detailed statistics related to modern digital solutions [12].

\section{Insufficient analysis of branch opportunities of the technology development in the middle-term prospect.}

The KPMG Company has conducted a research involving over 1,300 big companies worldwide, being industry leaders, and has found that despite of consideration of digital technologies as must have for further growth, 300 companies plan their introduction in long-term prospect only [13]. Experts believe that the Russian Federation is behind the introduction of modern digital technologies for 5-7 years averagely. As per business and society readiness to introduction of digital technologies, we take the 41 st position with significant gap to the leaders [10].

\section{Absence of complex approach to the technology introduction at an enterprise.}

Very few companies of high-tech economy sector consider digitalization as a complex solution for business management. In 2018, the share of high-tech activities in the Russian Federation was of $21.1 \%$. The digital twin technology may be applied only at the enterprises that have transferred many of their business processes into digital form, use MES-systems (Manufacturing Execution System) in production process management actively. In the Russian Federation, only $12.2 \%$ of enterprises use ERP-systems, $10.3 \%$ applies SRM-systems [12]. Just few of them understand rationality of digital twins and are ready for their implementation.

\section{E. Insufficient elaboration of information safety issues.}

Digital twin is an analogue of a physical object and possesses all its features. However, by nature it is a mathematic model in a continuous development, being no static object with a complete set of features. Many digital models are created with participation of Russian and foreign companies (for example, projects on exploitation), continuously corrected; and the information protection of such developments is very important. Protection of a real object copy is a priority task for enterprises, but it is hardly reflected in the Russian legal acts, based on the opinion of representatives of such Russian companies as RosAtom.

During the research in the field of digital twin implementation, the following research questions arose:

Which is a real readiness of industries to introduction of digital twins?

What are the factors limiting development and implementation of this technology?

May Russia be one of the leaders in introduction of digital solutions in industry?

Assumingly the answers to the above-mentioned questions will help to elaborate approaches to activation of industrial enterprises for introduction of the digital twin technology in those branches where it is mostly applicable; and in the middle-term prospect it will enable to create competitive advantages for the Russian companies.

\section{RESEARCH METHODS}

Initially the analysis of approaches to determination of a digital twin has been conducted. The digital twin types have been evaluated for the purpose of their applicability in different industries.

The term of a digital twin was introduced by NASA expert John Vickers. Further Prof. Michael Grieves used it to describe a model enabling product life cycle management (PLM) [1]. 
United Aircraft Corporation, Kamaz. It is worth to mention that the world statistic is around $16 \%$.

The following factors determine interest of the Russian companies in introduction of digital twins [14]:

- Designer optimization;

- Reduction of object design and construction self-costs;

- Reduction of time costs of a production cycle;

- Real time operation mode control with the following scenario analysis.

Efficiency of the technology introduction is considered from the point of short-term payback as an instrument of cost reduction and optimization of resource application.

\section{FINDINGS}

The enquiry conducted gave the following results. Of the focus group, $38 \%$ of the respondents showed interest in introduction of the digital twin technology in the future. Whereas the probability of the technology introduction in the middle-term prospect is assessed as of $17 \%$. Based on it a conclusion may be made that there are limiting factors with a high level of impact.

In addition, the enterprises were asked to assess their own readiness to introduction of the digital twin technology and to determine whether the digitalization level complies with the requirements. The results were relatively high, over $50 \%$ of the respondents in 6 industries declared their compliance with the digital economy requirements. Consumer goods industry shows the lowest rate of $16 \%$ (Fig. 1).

- equivalence (between different model representations);

- expansibility (ability to integrate, to add, or to replace models);

- fidelity (ability to describe the closeness to the physical product).

Within this research, we suppose to determine the digital twin as a set of mathematic models showing dynamic behavior of a real physical object or representing prototype of a future physical object.

The analysis of the statistic information and the results of the companies' focus group enquiry (340 enterprises of different industries in different regions of a country) showed that only $13 \%$ of the Russian enterprises perform product life cycle management (among those are Transneft, Aviaagregat, OAO, Perm Motor Plant, OAO). The world leaders are aerospace and defense industries with $24 \%$. In addition, this approach is well spread in such industries as oil extraction, oil production, electric energy, automotive industry, aircraft construction, shipbuilding. These industries are leaders in mastering digital twin technology, because for its introduction high level of digitalization of production, designing and business process management is required.

Applicability of digital twins in Russia is assessed at the level of $10 \%$. The following companies report planning their application: Rosatom, United Shipbuilding Corporation,

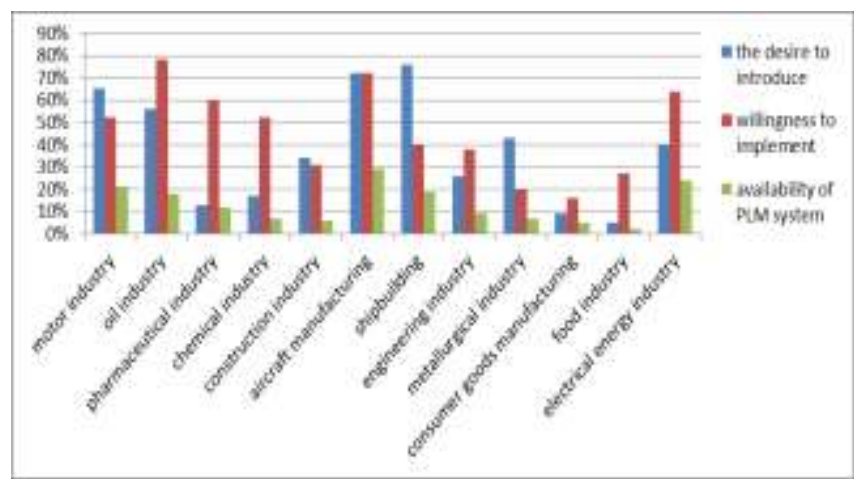

Fig. 1. Branch analysis of readiness to digital twin introduction

Enterprises actually implementing modern management approaches, in particular PLM-systems, contradict readiness of enterprises to introduce complicated digital solutions. In most of the branches, this management system is not applied. The market leaders only use PLM systems in some branches as oil producing, aircraft construction, shipbuilding, and electrical energy industry.

The Ministry for Digital Development, Communication and Mass Media of the Russian Federation has created the Road map of development of end-to-end digital technologies [14]. Smart Design (PLM-systems, digital twins, MESsystems) is among the main sub-technologies considered for 
with the involvement of public funds can show private business the effectiveness of the approach

May Russia become a leader in introduction of digital twins?

There are currently significant restrictions on the software market of the Russian Federation. Many software products that support PLM, SRM, MES systems are not available for implementation due to sanctions; some software products are very expensive to implement, taking into account the cost of maintenance. To ensure a leading position in this area, it is necessary to increase the number of Russian software in the market, to form an affordable price level. It is also necessary to create a product support system implemented in the form of training courses for companies' executives.

The effective use of digital twins is not possible without the initial digitalization of business processes, and it is becoming a priority for Russian industry. Given that the creation of a digital twin of a complex object at an enterprise with a high level of digitalization of processes takes about two years, in the middle-term prospect, the technology of digital twins is available only to a limited list of industries and enterprises with a high level of capitalization.

\section{References}

6. Actually insufficiently high level of business organization, change risks and company sustainability.

7. General underestimation of digital twin technology efficiency.

8. Digital twins are objects with low legal protection and information safety level, their introduction is considered also as business risks et al.

If we talk about the readiness of the industries of the Russian Federation to introduce digital twin technology, we can draw the following conclusion. Economic results of digital twins introduction are obvious for market leader enterprises only. For example, for oil producing enterprises the oil extraction coefficient increases for $10 \%$; for shipbuilding the costs for development and construction of objects reduce for 5-15\%. Nevertheless, Russian enterprises do not fully appreciate this technology from the position of the life cycle management.

Before the massive introduction of digital twin technology in industry, it is necessary to intensify the approach in the field of government management. A project for the creation of digital twin cities with a population of more than one hundred thousand people is under preparation. It will allow to assess the level of infrastructure, take into account the requirements for the overhaul of facilities, and mathematically calculate the economic stability of the city agglomeration. Creation of digital twins for assessment of building telecommunication networks efficiency can be one of the examples of international experience [4]. In addition, digital twin technologies may be applicable for simulation of the complex defense system, risk consideration, determination of development directions of enterprises of military industrial complex [8]. Positive experience in introducing technology
[1] N. Anwer, L. Mathieu, B. Schleich, and S. Wartzack, "Shaping the digital twin for design and production engineering", CIRP Annals Manufacturing Technology, no. 66, pp. 141-144, 2017.

[2] S. Haag and A. Reiner, "Digital Twin-Proof of Concept", Manufacturing Letters, 15, pp. 64-66, 2018.

[3] E. Negri, L. Fumagalli, M. Macchi, "A review of the roles of Digital Twin in CPS-based production systems", Procedia Manufacturing, no. 11, pp. 939-948, 2017.

[4] E. Oughton, "Building a Digital Twin: Testing the Effectiveness of Telecommunication Policies in a Virtual World", TPRC 46: The 46th Research Conference on Communication, Information and Internet Policy, 15 March 2018.

[5] R. Rosen, G. von Wichert, G.Lo, and K.D. Bettenhausen, "About the Importance of Autonomy and Digital Twins for the Future of Manufacturing”, IFAC-Papers OnLine, 48 (3), 567-572, 2015.

[6] "Shoumen Palit Austin Datta. Emergence of Digital Twins", Journal of Innovation Management, no. 5, pp. 14-34, 2017.

[7] R. Soni, D. Tanmay, Twinkle, and Madhulika Bhatia, "Digital Twin: Intersection of Mind and Machine", International Journal of Computational Intelligence \& IoT, 27 March 2019, vol. 2, no. 3, 2019.

[8] Timothy D. West and Mark Blackburn, "Is Digital Thread/Digital Twin Affordable? A Systemic Assessment of the Cost of DoD's Latest Manhattan Project”, Procedia Computer Science, 114, pp. 47-56, 2017.

[9] Ansys. Digital Twin [Electronic resource]. Available at: https://www.ansys.com/products/systems/digital-twin.

[10] Global Innovation Index 2016, Winning with Global Innovation [Electronic resource]. Available at: https://www.wipo.int/publications/en/details.jsp?id=4064\&plang=RU.

[11] Gartner Top 10 Strategic Technology Trends for 2020 [Electronic resource]. Available at: https://www.gartner.com/smarterwithgartner/gartner-top-10-strategictechnology-trends-for-2020/.

[12] Federal State Statistic Service, Digital economy of the Russian Federation [Electronic resource]. Available at: https://www.gks.ru/anketa1-4.

[13] KMPG. Digital Transformation [Electronic resource]. Available at: https://home.kpmg/xx/en/home/services/advisory/digitaltransformation.html. 
[14] Roadmap for the development of "End-to-end" Digital technology. "New production technology" [Electronic resource]. Available at: https://digital.gov.ru/uploaded/files/07102019npt.pdf.

[15] Special solutions with the Digital Enterprise Suite [Electronic resource]. Available at: https://new.siemens.com/global/en/company/topicareas/future-of-manufacturing/digital-enterprise.html.
[16] Strategy of digital economy of Russia till 2035 [Electronic resource]. Available at: http://static.government.ru/media/files/ 9gFM4FHj4PsB79I5v7yLVuPgu4bvR7M0.pdf. 